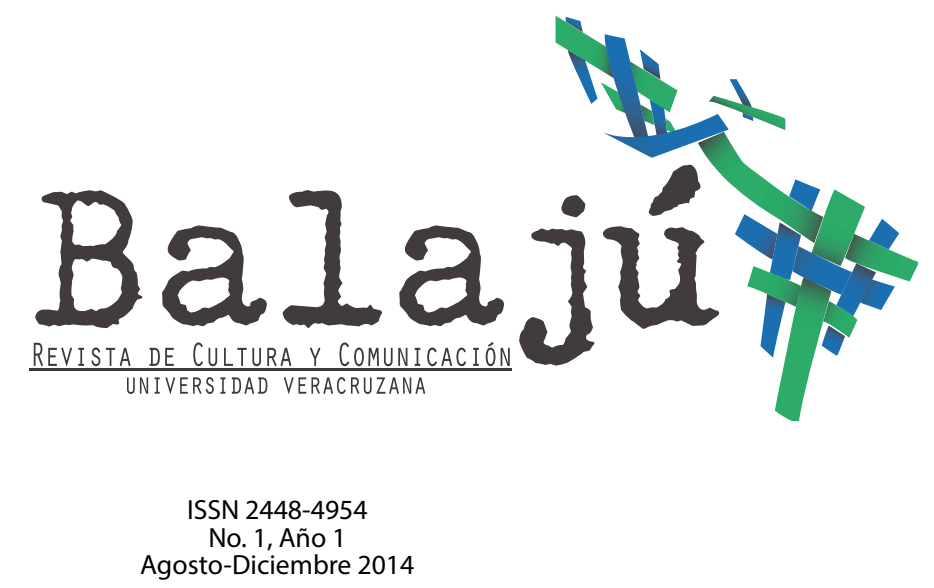

\title{
El modelo del entretenimiento educativo en la webnovela, caso Historias de culpa (2000)
}

Raquel Guerrero Viguri

Universidad Veracruzana, México

rgviguri@gmail.com

\section{RESUMEN}

El presente texto hace un breve análisis retomando elementos de la metodología histórico-estructural respecto la novedosa propuesta de producción que aportó la primera webnovela mexicana, Historias de culpa (2000), así como la relevancia de conocer el estilo de su realizador, Miguel Sabido, para poder comprender tanto las temáticas abordadas como la manera en la que fueron planteadas, correspondiendo al modelo del entretenimiento educativo y a la teoría del Tono creadas por él mismo desde su trabajo en las telenovelas de Televisa de los años setenta, conocidas como telenovelas educativas o didácticas.

\begin{abstract}
This paper makes a brief analysis reprising elements of historical-structural approach regarding the new proposal production provided the first Mexican webnovela, Historias de culpa (2000) and the importance of knowing the style of its director, Miguel Sabido, to understand both the issues addressed and the manner in which they were presented, corresponding to the model of educational entertainment and theory of Tone created by himself from his work in telenovelas from Televisa at 70, known as educational or soap operas didactic.
\end{abstract}

\section{PALABRAS CLAVE}

webnovelas, telenovelas, entretenimiento educativo, Internet

\section{KEYWORDS}

webnovelas, soap operas, educational entertainment, internet 


\section{El modelo del entretenimiento educativo en la webnovela, caso Historias de culpa (2000) ${ }^{1}$}

Por Raquel Guerrero Viguri

La incursión del melodrama al Internet ha sido un proceso lento en la industria del entretenimiento latinoamericano. Si bien España ha destacado como un país donde series y telenovelas se producen específicamente para las audiencias de la red desde hace una década, en la actualidad poco se ha experimentado en México al respecto, pese al reconocimiento internacional que tiene en cuanto a la producción y distribución de telenovelas.

Sin embargo existió un título que intentó adaptar el melodrama televisivo a un nuevo formato para ser visto y consumido únicamente desde Internet a principios del nuevo milenio, una propuesta mexicana que experimentó en una época donde las condiciones tecnológicas no resultaron óptimas para su consumo masivo, pero que sentó un precedente tanto por su producción como por los temas ahí abordados, característicos del estilo de su creador: Miguel Sabido, el padre de la telenovela didáctica en la Televisa de los años setenta.

Para esta reflexión se tomaron en cuenta dos aspectos del marco teórico metodológico propuesto por Enrique Sánchez, el análisis histórico-estructural (1992). Luego de hacer un recorrido por los diversos paradigmas desde los que han sido estudiados, Sánchez entiende la necesidad de realizar una vigilancia epistemológica a los medios de difusión que se base tanto en las reflexiones teóricas como en la investigación concreta que arroje datos, ya sea cuantitativos o cualitativos, acompañadas de un trabajo de análisis, síntesis, deducción, inducción. Así propone una metodología histórico-estructural para el análisis sociológico de los medios de difusión. Este análisis está compuesto por un enfoque histórico-dialéctico que toma en cuenta a la organización social y la producción como formas cambiantes, en movimiento y transición. El aspecto crítico se enfoca en la búsqueda e identificación de las contradicciones sociales partiendo de procesos de estructuración/destructuración-reestructuración histórica a partir de las mediaciones que atraviesan el objeto de estudio, para lo cuál se debe recurrir a teorías que se ajusten a cada una de estas mediaciones. Para esta reflexión se tomarán en cuenta únicamente la organización social, en la figura del productor y la producción como elementos relevantes para la comprensión de un fenómeno comunicativo, en este caso la webnovela.

1.- Una versión recortada de este artículo fue presentada en forma de ponencia en el XXI Congreso Latinoamericano de Investigadores de la Comunicación ALAIC, en el grupo de interés "Ficción televisiva y narrativas transmedia”, realizado en la Pontificia Universidad Católica de Perú del 6 al 8 de agosto de 2014. 


\section{Historias de culpa (200o)}

Historias de culpa fue una producción creada por Miguel Sabido para el hoy extinto portal Alo.com, propiedad de los hermanos Guillermo y José Antonio Cañedo White, en el año 2000. Resulta complicado describir una sinopsis de lo que fueron los 82 segmentos de Historias de culpa, puesto que quedan pocos registros de esta webnovela, ya que el portal que la alojó duró únicamente un año y medio en la red, antes del fracaso comercial de su propuesta. Incluso su creador reconoce que a trece años de realizada únicamente conserva el material que puso a la disposición de este estudio, que son 13 segmentos con duración total de 22 minutos. También se encontró en el portal Youtube un clip de 4:02 minutos con otra parte de la historia, que posiblemente sea anterior al material conservado por el productor. Este video fue subido por el usuario "oscarsargent" el 25 de abril del 2007, con la descripción "Trailer de la webnovela". La diferencia es que en los primeros aparecen subtítulos y audio en español, y en el segundo en inglés. Cada segmento tenía una duración aproximada de 5 minutos y era subido los días lunes.

Existe sin embargo una sinopsis con la que fue presentada en la nota del diario Reforma "Lágrimas en la red": "Dos mujeres sufren cambios circunstanciales en sus vidas. Una de ellas es Fanny, quien deberá enfrentarse a la sociedad por enamorarse de un neonazi. La otra mujer es Anita. Ella luchará por defender su actual matrimonio y olvidarse de su ex esposo, contagiado de sida" (Marín, 200ob).

En el material disponible se pueden ver además otras historias como la de Pablo, un joven ex guerrillero que al ser herido fue a refugiarse en casa de su abuela y de Julia Jiménez, madre, quien rechaza a su hijo independientemente de considerarlo un delincuente. Las historias se unen con Roger, un joven judío que está por casarse con una modelo de nombre Samantha, amiga de Fanny, ante el rechazo de su familia, y Renato Davidoff, tío de Roger y Fanny y médico retirado que trata a Pablo, quien se lamenta por la pérdida de sus dos hijos. Renato además de ser amigo de Luis, sacerdote católico hermano de Pablo, es un sobreviviente del holocausto.

\section{El estilo del creador}

Enrique Sánchez considera dentro de su metodología para estudiar a los medios de difusión a la organización como una mediación importante. Se trata de conocer los esquemas que surgen en los medios como organizaciones complejas: "mediaciones de las profesiones, de las burocracias, 
de la tecnología, de los patrones de propiedad y control, de los modos de producción, de las articulaciones institucionales de estas organizaciones con otras y con las demás instancias sociales, etc.” (Sánchez, 1991, p. 97). Apelando a los modos de producción y a quienes son responsables de ellos, el enfoque de esta mediación toma en consideración la relevancia de entender cómo ha sido la formación de los individuos que ocupan cada rol dentro de un equipo de trabajo. Entonces, “¿conocer acerca de los orígenes sociales, los estilos de vida y las vidas profesionales de los productores, directores, guionistas y escritores ayuda a explicar por qué los teledramas toman la forma que tienen? La respuesta es sí y parece ser más útil en el caso de materiales de ficción que en el caso de la televisión de actualidad" (Murdock, 1998, p. 74).

Miguel Sabido Ruizsánchez nació el 20 de noviembre de 1937 en la ciudad de México. Hijo de Miguel Sabido, un indígena que aprendió a hablar castellano a los 13 años para después convertirse en catedrático universitario y sindicalista, y de Julia Ruizsánchez, maestra misionera vasconcelista. Según lo describe el mismo Sabido, creció en medio de un ambiente donde aprendió a valorar la cultura y el respeto por México. Fue vecino de Xavier Villaurrutia, María Antonieta Rivas Mercado era la mejor amiga de su madre; sobrino de Rodolfo Usigli, nieto de Julia Nava, mujer fundadora de la carrera de trabajo social en el país, alumno de Emilio Carballido, y discípulo de Salvador Novo.

Con ese bagaje, Miguel Sabido ingresó en 1956 a la Universidad Nacional Autónoma de México a estudiar Lengua y Literatura Hispánicas, con especialidad en arte dramático. Tres años más tarde dirigió su primera obra de teatro, justo un año después de que Telesistema Mexicano estrenara la primer telenovela oficial de México.

Por invitación de Ernesto Alonso, Sabido formó parte del grupo de escritores que dieron forma a los melodramas históricos como La tormenta (1967) y La constitución (1970), sin embargo motivado por el éxito peruano Simplemente María (1967), comprendió que los medios de comunicación podían tener un uso social más allá del entretenimiento, por lo cuál propuso un modelo de telenovela educativa que le permitiera comprobar esta hipótesis. Así, con apoyo de Emilio Azcárraga Milmo produjo Ven conmigo (1975), Acompáñame (1977), Vamos juntos (1979), Caminemos (1980), Nosotras las mujeres (1981), Por amor (1983) y Los hijos de nadie (1997). La primera trató sobre la alfabetización para los adultos; las tres siguientes enfocaron al tema de la planificación familiar, la paternidad responsable, el desarrollo integral de la niñez y la sexualidad en los adolescentes; la siguiente sobre la igualdad de las mujeres; en las últimas se abordó la alfabetización de personas del campo que migran 
a la ciudad y la situación de los niños de la calle.

En el trabajo de Miguel Sabido se distinguen temáticas recurrentes y un reparto con actores provenientes principalmente del teatro. Estos elementos corresponden, estratégicamente, a la puesta en práctica de su teoría tonal.

Esta teoría comunicacional parte de la idea de que "todo lo que vibra existe. Todo lo que existe vibra. La condición del ser es la vibración" (Sabido, 2002, p. 30). Puesto que el ser humano también lo hace, sus vibraciones se ordenan mediante un diagrama vibracional, constituido por unidades, que tienen patrones de organización determinados con tres características compartidas: 1) tendencia a sintonizar los flujos del entorno, 2) transducción activa, es decir, capacidad de transformación gracias a la intervención de una fuerza externa de energía, y 3) emisión del entorno vibracional de flujos transformados. Entonces parte de la premisa de que el ser humano es poseedor de tres centros transductores: reptil, límbico e intelectual, apoyado en las teorías de Daniel Goleman.

La teoría del tono propone que es posible la organización de elementos de flujos culturales intencionalmente creados por el hombre, y sintonizarlos por un parámetro de sintonía de unidades vibracionales con el fin de reforzar repertorios de patrones, lo cuál permita "una mejor ecualización" (Sabido, 2002, p. 52) de la especie humana. Para lograr una emisión de flujos conciente se trabaja a partir de nodos, conectados a partes del cuerpo humano.

En el caso de los medios de comunicación, y más específicamente en la televisión, el emisor puede ser un productor, un actor, un director o un escritor que sea capaz de concentrar y transmitir energía a cada nodo, provocando así un tipo de comunicación intelectual o racional (si se trata del cerebro humano), emocional y sentimental (cerebro límbico) e instintivo (cerebro reptil). Para la transmisión de esa energía tendrá a su disposición un formato específico, puesto que cada uno contiene un diagrama vibracional específico. Puede ser un concierto, una conferencia, una película, o una telenovela. Por último es el otro ser humano, el que recibe todas las energías, quien genera el tono, que será de mayor o de menor intensidad de acuerdo su entorno particular de flujos.

Así es posible entender que Sabido, al crear este modelo teórico, pensara en el entretenimiento como el lugar para su aplicación: "El entretenimiento es el nivel de coincidencia de las vibraciones en el flujo con el diagrama vibracional del receptor" (2002, p. 153). Así, a mayor tono, mayor intensidad en el entretenimiento.

El entretenimiento entonces, puede ser el portador ideal de cualquier tipo de mensajes. Para ello Sabido recurrió a las teorías del apren- 
dizaje social de Alberto Bandura y la teoría dramática de Eric Bentley.

La primera propone cuatro etapas o procesos para que a través de una telenovela pueda haber un proceso de aprendizaje mediante la identificación con personajes modelo: una etapa de atención, otra de retención, otra de reproducción motora y una etapa motivacional (Torres Aguilera, 1994). Por otra parte la segunda teoría contempla a la telenovela como un melodrama estructurado que a través del desarrollo del tema, la anécdota y los personajes intenta establecer una relación entre el público y el efecto que en él causa la producción: "el melodrama, entonces, vendría a ser una reflexión ilustrada sobre lo que es bueno y malo en el ámbito de los valores de convivencia social” (Torres Aguilera, 1994, p. 48).

Al llevar a la práctica la teoría del tono, Sabido considera tres elementos para la creación de un título:

1.- Un marco teórico, es decir, se plantea una hipótesis de deberá cumplirse.

2.- La ordenación del flujo de codificación

3.- La evaluación de los efectos del flujo

Para esto retoma el modelo de comunicación de una telenovela comercial, que tiene cinco componentes:

1.- Comunicador (anunciante)

2.- Mensaje (incita a la compra del producto del anunciante)

3.- Medio (la telenovela)

4.- Receptor (televidente)

5.- Respuesta deseada (ratings y ventas del producto)

Sabido, sin embargo, incorpora cinco elementos más a este modelo para adecuarlo a su teoría, tomando en cuenta que las temáticas que aborda giran en torno a su utilidad social. Queda así:

1.- Primer comunicador (comercial)

2.- Primer mensaje (incita a la compra del producto)

3.- Medio (la telenovela)

4.- Receptor (televidente)

5.- Primera respuesta (la compra del producto)

6.- Segundo comunicador (social)

7.- Segundo mensaje (acude a la estructura)

8.- Medio (la telenovela)

9.- Receptor (televidente)

10.- Segunda respuesta (Refuerzo del valor social, asistencia a la infraestructura) 
Para el desarrollo de los últimos cinco componentes, Sabido contempla la participación de alguna institución o instancia pública, para apoyar al refuerzo de los valores promovidos en esta parte.

De la misma forma en la que se escribieron las telenovelas históricas, en las de beneficio social existen dos tramas y personajes para ambas; los de la primera trama se encargarán de cumplir con los primeros cinco componentes, del tipo comercial (que apunta a los nodos límbicos, emocionales), y los de la segunda desarrollarán los otros cinco, del tipo social (que apunta a los nodos humanos, intelectuales y racionales). Para lograrlo, este segundo grupo de personajes pasarán por cinco etapas para lograr su cometido:

1.- La persona sufre por un problema que no puede resolver.

2.- Encuentra una forma de solucionar dicho problema a través de una infraestructura pública relacionada de manera directa con el valor social que se promueve.

3.- Ingreso a la infraestructura con refuerzos tanto positivos como negativos.

4.- Aparece una crisis que obliga a la persona a dejar de usar la infraestructura.

5.- El triunfo, donde se disfruta el logro y se recibe una recompensa. (Garnica, 2011).

\section{Requerimientos de producción}

Como parte de la misma mediación organizacional, para efectos de esta investigación se contempla que: "la producción de telenovelas no se entendería sin considerar la distribución interna del poder y los modos en que empresas, agentes especializados y los mismos productos significantes se insertan y actúan como parte de estructuras de distribución del poder a escalas macrosociales" (González, 1998, p. 77). Sin embargo, ¿̇cómo se observa esto es la producción de una webnovela?

En la nota del periódico Reforma "Lágrimas en la red", se afirma que:

"En comparación con una telenovela, el equipo humano que se requiere para realizar una webnovela es mucho menor, ya que las necesidades técnicas son distintas, además de que todavía no tienen el apoyo de departamentos como el de diseño de vestuario y otros que en el trabajo de televisión son básicos”. (Marín, 200ob)

La periodista también establece cifras comparativas entre una telenovela y una webnovela: 


\begin{tabular}{|c|c|}
\hline \multicolumn{2}{|c|}{ Equipo humano en producción } \\
\hline Telenovela & 18 personas \\
\hline Webnovela & 13 personas \\
\hline \multicolumn{2}{|c|}{ Elenco } \\
\hline Telenovela & 80 actores \\
\hline Webnovela & 23 actores \\
\hline \multicolumn{2}{|c|}{ Por capítulo } \\
\hline Telenovela & 25 escenas \\
\hline Webnovela & 100 fotografías \\
\hline \multicolumn{2}{|c|}{ Costo } \\
\hline Telenovela & 1 millón de pesos \\
\hline Webnovela & 60 mil pesos \\
\hline \multicolumn{2}{|c|}{ Tiempo de realización } \\
\hline Telenovela & $\begin{array}{l}\text { Por día se graban } 22 \text { minutos en foro y } \\
15 \text { en locación }\end{array}$ \\
\hline Webnovela & $\begin{array}{l}1 \text { día de fotografías, otro de grabación de } \\
\text { audio y tres para posproducción. }\end{array}$ \\
\hline
\end{tabular}

En cuanto al recurso humano, las cifras parecen no tener mucho sentido, sobre todo si la misma reportera afirmó antes que las diferencias en el personal eran considerables. Por ello se sugiere que en la edición de la nota fueron invertidos los rubros "equipo humano de producción" y "elenco", pues resulta más creíble que en el primero la telenovela tenga 80 personas que incluyan justamente un equipo de diseño de vestuario, y que el elenco disminuya a tan sólo cinco actores menos.

Suponiendo que esto sea cierto, la reducción de 80 a 23 personas involucradas en el proceso de producción advertiría que una persona fue capaz de realizar uno o varios roles, tal como Sabido, quien según la reportera figuró como productor, escritor y guionista, además de haber realizado el scouting de las locaciones. Como él mismo lo explicó: "no tenía estudios para hacer la webnovela, pero quise mantener mi independencia, entonces fuimos haciendo las fotografías donde pudimos, en casa de amigos y en la mía y sólo cambiamos las cortinas y todo" (Marín, 2000).

Contrario a su trabajo en telenovelas, donde actrices como María Rojo fueron constantes no sólo en la época Televisa, sino también en trabajos posteriores, como en el caso de Aprender a vivir (2012), Historias de culpa contó con pocos actores reconocidos en la televisión comercial, debido a que o estaban ocupados o tenían exclusividades con alguna televisora, así que se acudió a Lorena Rivero, actriz que trabajó en Televisión Azteca desde las primeras telenovelas de la empresa. 
En palabras de Sabido: "Tuvimos que inventarnos estrellas en la mayoría de los casos. Fuimos a escuelas de teatro y sacamos a gente que participó en obras infantiles" (Marín, 200ob). Debido a su formación y a los requerimientos sobre el manejo de las energías de los actores, no parece casual que se haya acudido a escuelas de teatro antes de ir al CEA o al CEFAC, escuelas de actuación de Televisa y Televisión Azteca respectivamente.

Como ejercicio comparativo se muestran cifras de la más reciente telenovela de Sabido, Aprender a vivir (2012), para entender las diferencias en cuanto al número de personal empleado para una producción televisiva y una para la web.

Aprender a vivir (2012) fue realizada por Televisión Educativa y Producciones Nuevo Sol, transmitida por Aprende TV, y constó de 60 capítulos de 22 minutos cada uno. A continuación se enlista la cantidad de personas y los roles que desempeñaron, que difieren de número de personal que utilizan empresas como Televisa para una telenovela:

\begin{tabular}{|c|c|}
\hline Rol & Número \\
\hline Productor General & 1 \\
\hline Productor TV Educativa & 1 \\
\hline Productora Nuevo Sol & 1 \\
\hline Dirección de cámaras & 1 \\
\hline Dirección de escena & 1 \\
\hline Productor en línea & 1 \\
\hline Coordinador de producción & 1 \\
\hline Jefe de producción & 1 \\
\hline Continuidad & 1 \\
\hline Planeación & 1 \\
\hline Asistente de dirección & 1 \\
\hline Fotografía & 1 \\
\hline Edición & 1 \\
\hline Música original & 1 \\
\hline Musicalización y diseño de audio & 1 \\
\hline Utilería & 2 \\
\hline Ambientación & 3 \\
\hline Gerente de locaciones & 1 \\
\hline Corrección de formato & 1 \\
\hline Diseño de vestuario & 1 \\
\hline Diseño de imagen & 1 \\
\hline Asesora & 1 \\
\hline
\end{tabular}




\begin{tabular}{|c|c|}
\hline Diálogos & 2 \\
\hline Elenco & 26 \\
\hline Asistente de producción & 5 \\
\hline Asistente de locación & 1 \\
\hline Staff iluminación & 6 \\
\hline Camarógrafos & 4 \\
\hline Jefe de piso & 1 \\
\hline Asistente de cámaras & 3 \\
\hline Microfonistas & 2 \\
\hline Eléctrico & 1 \\
\hline Ingeniero de estudio & 1 \\
\hline Ingeniero de unidad móvil & 1 \\
\hline Videotape & 1 \\
\hline Coordinación de vestuario & 1 \\
\hline Asistente de vestuario & 2 \\
\hline Maquillaje y peinados & 4 \\
\hline Apuntador & 1 \\
\hline Coordinador de transportes & 1 \\
\hline Choferes & 6 \\
\hline Efectos especiales & 1 \\
\hline
\end{tabular}

En total son 101 personas trabajando para una producción de naturaleza pública, de acuerdo a su plataforma de transmisión, y no comercial, lo que además se acerca a la premisa aquí establecida sobre las cifras en la nota de Reforma: 80 personas en una telenovela por 23 de la webnovela.

De acuerdo a lo expuesto en el cuadro comparativo, el costo de una webnovela resulta menor al de una telenovela comercial. Si bien esta información no pudo ser confirmada, sí se sabe que aún en sus años de trabajo en Televisa, Miguel Sabido aprendió a trabajar con un bajo presupuesto y apoyado por figuras de patrocinio comercial, lo cuál para Rogers, Singhal y Brown era parte de su modelo básico de trabajo: "su contenido melodramático, los temas y los subtemas, los bajos costos de producción" (1993, p. 51)

Esto es en cuanto a la parte organizacional. En cuanto al estilo del productor el mismo Sabido declaró que Historias de culpa apareció en el momento en el que su línea de investigación iba en torno a los usos sociales del Internet (2002), por lo tanto la webnovela corresponde a la aplicación directa de su teoría en otro medio de comunicación. A través de una mezcla de géneros, Historias de culpa es una propuesta distinta a una telenovela "aunque su concepto rescata elementos no sólo de este género sino de la radio y la fotonovela, pues consiste en la secuencia de 
fotografías con animación y el montaje de audio el cuál exalta las emociones de los personajes" (Marín, 200ob). Según las palabras de Sabido este no fue un hecho fortuito, pues además se pensó en una forma de descarga más rápida de lo que la banda ancha en aquel tiempo permitía para un archivo de video. Hasta la aparición del libro El Tono, el productor menciona que en esa fecha se habían publicado cuarenta capítulos de los 82 realizados y difundidos en el portal Alo.com

Como se mostró anteriormente el entretenimiento educativo en las telenovelas respeta la estructura melodramática comercial y agrega otra donde se da el conflicto social, es decir, el bien contra el mal y la temática de duda. Éstos elementos son retomados en la webnovela para hablar de la tolerancia por medio de temáticas específicas: el neonazismo, la religión, la guerrilla y el SIDA, para lo cuál se acudió a CONASIDA como la instancia pública que canalizaría las inquietudes de la audiencia. Propuesta audiovisual

En la cortinilla del inicio Historias de culpa se presenta como "la primer telenovela digital original de Miguel Sabido”. Antes de que todo producto de entretenimiento lanzado desde Internet fuera nombrado con el prefijo web, el adjetivo digital resultaba lo más común, entendido como la forma de convertir documentos, ya sea escritos, gráficos o audiovisuales en datos numéricos que pueden ser modificables y reproducibles infinitamente. Al principio se le describió de acuerdo a esta característica puesto que, según lo expresado por Sabido, este fue su primer acercamiento la edición no lineal, es decir, desde una computadora y sin haberse grabado en videotape:

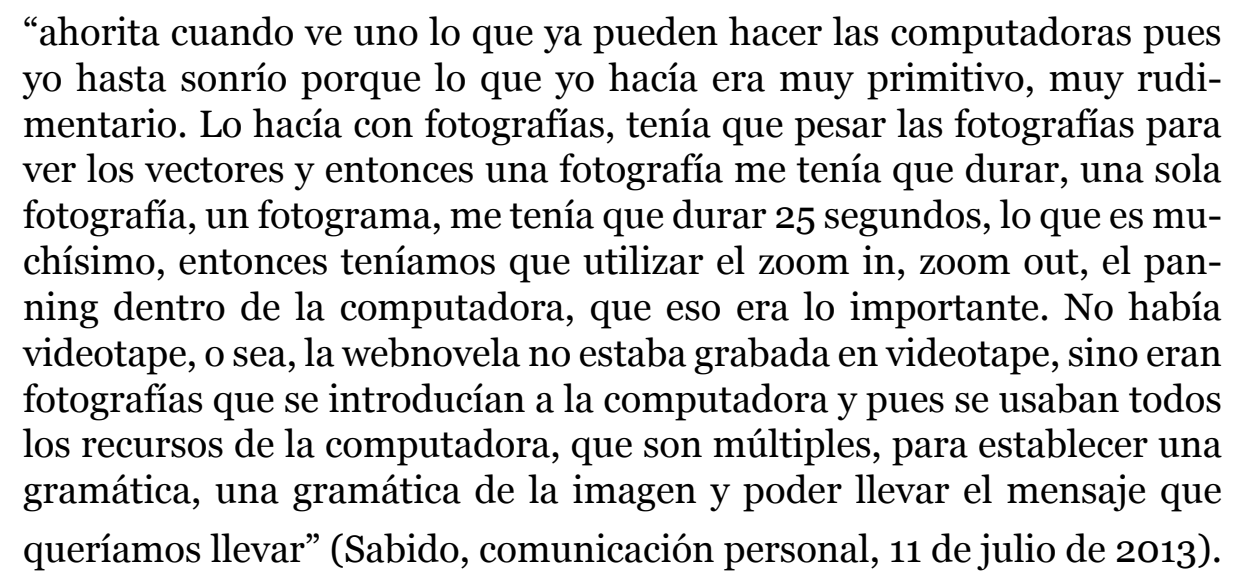

Si lo que dice Alejandro Piscitelli es cierto: "la televisión no es una tecnología ni un sistema estético sino un mecanismo humano de producción de sentido" (1998, p. 39), ¿cuál podría ser el sentido que construyó Miguel Sabido en Historias de culpa, en su búsqueda por encontrar el uso 
social de un medio como el internet?

Se estudiaron 3 secuencias: La primera secuencia de 1 minuto de duración, la segunda de 2 minutos y la tercera de 2 minutos con 6 segundos. Es decir, se necesitaron 21 fotogramas para un minuto, 31 fotogramas para dos minutos de la segunda, y 26 para el tercero, 5 menos que el anterior pese a que dura seis segundos más.

Para Guillermo Orozco los movimientos de cámara, la iluminación y los efectos especiales caracterizan una producción y la diferencian de otra; para él tanto los criterios de producción como los ritmos, sonoridades y demás efectos especiales determinan las marcas de un productor, su estilo personal (2008). En las secuencias estudiadas se puede percibir no sólo un estilo sino la creatividad con la cuál fue resuelta la ilusión de movimiento que de manera natural da el videotape. Para ello se utiliza una variedad de encuadres y efectos, que enlistadas, podrían parecer excesivas, sin embargo su uso otorga un ritmo determinado según la situación planteada.

Tal como lo establece Scolari (2008), los productos hechos para las pantallas de computadoras o dispositivos carecen de tomas abiertas, y las secuencias analizadas son ejemplo de ello. Las tomas más frecuentes en los fotogramas son los planos medios, separados entre sí por transiciones como disolvencias y deslizados de adentro hacia fuera, y los acercamientos, para dar énfasis a la gesticulación de los actores.

La disolvencia es empleada cuando se trata de encuadres similares, donde lo que varía es la posición o la expresión del actor, o bien la intención de suavizar las discusiones que se escenifican en las tres secuencias. Por el contrario, la transición deslizada es frecuente para sugerir tensión, enojo o angustia en los personajes, tal es el caso del fotograma 16 de la secuencia de Fanny o el fotograma 12 en la secuencia de Pablo. En el caso del enojo y la angustia hay otro factor además del deslizado que sugiere este sentimiento: el cambio de color. En el fotograma 8 de la secuencia de Fanny se presenta cuando ella le pide al policía que Rudolph la suelte; en la secuencia de Pablo en el fotograma 27, en el recuerdo de cuando fue herido, y en el fotograma 24 de la última secuencia, cuando Debbie se molesta porque Samantha la llama "tiíta", aunque en éste caso la toma se vuelve amarilla, y en los anteriores es roja. Podría decirse que dan cierta temperatura a la situación. El fotograma de otro color también marca el fin de la secuencia en los dos primeros casos; en el cierre de la secuencia Fanny es amarillo y en el cierre de la secuencia Pablo es rojo.

También hay movimientos en la entrada y salida de los subtítulos, si bien no en todos los casos sí son notables cuando el fotograma tiene más duración y en él se aplican dos efectos, como entrada con disolvencia 
y segundos después un acercamiento, que sugiere el ritmo que imprime la voz de los actores. Las palabras dichas con mayor fuerza son ilustradas con un cambio de color en las letras, de blanco a amarillo, y también en fotogramas como el 5 de la primera secuencia, varía hasta en tamaño.

En el fotograma 9 de la secuencia de Samantha se ilustra una única toma subjetiva, es decir, aquella donde la cámara simula dar el punto de vista de un personaje. Con dos fotogramas casi iguales se simula el movimiento de la mano de Debbie cuando señala a Samantha, quien habla por teléfono. Para ilustrar acercamientos detallados, como en los primeros fotogramas de la segunda secuencia, se prefiere ilustrar el momento en el que Julia abre la puerta con tres fotografías que con una con movimiento.

También es importante señalar que sólo en una de las tres secuencias descritas hay música de fondo. En la secuencia de Fanny sólo se escuchan murmullos de las personas del hotel, lugar donde se lleva la acción, y en la tercera no hay nada más que las voces de Roger, Debbie y Samantha. En cambio en la secuencia de Pablo se ilustra desde el principio el sentir y la acción de Julia, su decisión de enfrentar a su hijo ante la duda de si quedaría inválido o no, y después, al hablar con él, el fondo cambia y la música produce una sensación de suspenso hasta el final.

En opinión de Lorena Rivero, una de las actrices entrevistadas en el estreno de Historias de culpa: "el trabajo se enfoca más en reacciones del rostro, tienes que modular la voz, subir y bajarla, dar tonos y no estar plana. En una telenovela estás más en contacto con el público, el cambio en la webnovela tienes que actuar más con tus reacciones, mostrar la actitud con los ojos, con las manos, en fin" (Marín, 2000). Este análisis da cuenta de que, en efecto, así es como fueron dirigidos los actores y cómo sus actuaciones fueron reforzadas con los elementos visuales descritos.

Antes de Historias de culpa la última telenovela de Miguel Sabido había sido Los hijos de nadie (1997), que tiene ciertos elementos recurrentes en las telenovelas del modelo mexicano, como los sets de 3 paredes. Sin embargo, dado que como fue especificado no se contó con ningún estudio disponible para la grabación de la webnovela, se jugó más con los espacios disponibles, como un hotel real (de hecho, hasta se muestra el nombre del hotel Krystal) o casas reales prestadas para la producción. De acuerdo al recurso también es factible pensar que se emplearon una o dos cámaras fotográficas para realizar todas las tomas. Otro elemento propio del modelo mexicano es el incorporar un tema musical con cantantes reconocidos para las cortinillas de entrada. Sabido aplicó esta fórmula sin que se tratara de los artistas de moda (en el caso de Los hijos de nadie el tema fue interpretado por Rossie Montenegro, niña de origen cubano que cantaba y actuaba, por lo que llevaba un rol protagónico dentro de la 
historia), y lo mismo se aprecia en Historias de culpa. La cortinilla que se presenta al inicio de la grabación de 22 minutos, se muestran los créditos de los actores al ritmo de "Polvo enamorado", tema musical interpretado por José José en el año 1981.

Cabe señalar que debido a la desaparición del portal Alo.com y a que el productor, Miguel Sabido, no cuenta con los datos exactos, resulta difícil acercarse a una cifra de usuarios que hayan seguido al menos un segmento de la webnovela, sin embargo si hay conocimiento de cómo era la interacción entre la producción y los usuarios asiduos a la historia, por otras vías además de los foros que estaban abiertos en el canal donde se colgaba Historias de culpa:

\begin{abstract}
"sí teníamos interacción con el espectador, sobre todo que hacía preguntas al respecto, la mayoría de las preguntas que teníamos eran acerca de, fíjese usted que curioso, eran acerca del neonazismo, posiblemente, no sé, no sé por qué, pero nos preguntaban sobre el neonazismo y sobre el SIDA, nos preguntaban que si, me acuerdo de uno de los correos que decía, claro eran correos, no era blog verdad, entonces eran correos muy rudimentarios y esa era la interacción" (Sabido, comunicación personal, 11 de julio de 2013).
\end{abstract}

Ya que estos foros desaparecieron junto con el portal en el año 2001, no es posible comprobar si los planteamientos de Sabido respecto a la teoría tonal se aplicaron íntegramente en Historias de culpa, es decir, si los personajes cumplieron con los 5 puntos antes mencionados, o si los usuarios respondieron a los estímulos vibracionales para acudir a instancias como CONASIDA.

\title{
A modo de conclusión
}

Como se puede observar la gramática empleada por Miguel Sabido para contar este melodrama fue algo poco común, y aunque fuera de manera rústica, resultó innovador a todo lo antes hecho por él. Empleó recursos técnicos diferentes, tanto en la captura de imágenes como en el audio y en la presentación, y es posible decir que creó un estilo que en aquel momento fusionó fotonovela con radionovela pero que en su más reciente trabajo, Aprender a vivir (2012), aparece de nueva cuenta pero con elementos similares al cómic. En el capítulo 3 de esta telenovela, por ejemplo, se ilustra un accidente automovilístico a partir de imágenes congeladas con movimientos, en blanco y negro pero con manchones rojos cuando se muestran los heridos del choque. Es la misma manera de usar las imágenes que ya experimentó en Historias de culpa, pero evidentemente con otra tecnología y para un medio distinto. Sin embargo es posible concluir que la realización de la webnovela lo hizo crear otra 
gramática audiovisual, sin traicionar su modelo del entretenimiento educativo, que todavía se hace evidente en sus trabajos posteriores.

\section{BIBLIOGRAFÍA}

Garnica, A. (2011). Las tele-visiones de un visionario: cómo Miguel Sabido contribuyó a la telenovela mexicana y al entretenimiento educativo. En Telenovelas en México. Nuestras íntimas extrañas (pp. 95-120). México: Grupo Delphi.

González Molina, G. (1998). Profesioines en trama: análisis de producción de telenovelas. En González, J. (comp.), La cofradía de las emociones (in)terminables: miradas sobre telenovelas en México (págs. 79-98). Guadalajara, Jalisco, México: Universidad de Guadalajara.

Murdock, G. (1998). Fabricando ficciones: elementos para el estudio de la producción de dramas televisivos. Estudios sobre las Culturas Comtemporáneas , II (4-5), 67-93.

Marín, N. (2000 15-octubre). Lágrimas en la red. Reforma.

Marín, N. (2000 15-octubre). Cibernovela de fabricación casera. Reforma.

Piscitelli, A. (1998). Post/televisión. Ecología de los medios en la era de internet. Barcelona, Buenos Aires, México: Paidós.

Orozco, G. (2008). Audiencias y pantallas. Lo nuevo, lo viejo y lo que viene. En La mirada de Telemo: http://revistas.pucp.edu.pe/index. php/lamiradadetelemo

Rogers, E., Singhal, A., \& Brown, W. (1993). Ficción, placer y desarrollo. Chasqui. Revista Latinoamericana de Comunicación (46), 50-56.

Scolari, C. (2008). Hipermediaciones. Elementos para una teoría de la comunicación digital interactiva. Barcelona, España: Gedisa.

Sabido, M. (2002). El tono. Andanzas teóricas, aventuras prácticas, el entretenimiento con beneficio social. México: Universidad Nacional Autónoma de México.

Sánchez, E. (1992). Medios de difusión y sociedad. Notas críticas y metodológicas. Guadalajara, Jalisco, México: Universidad de Guadalajara.

Torres Aguilera, F. (1994). Telenovelas, televisión y comunicación. México, México: Ediciones Coyoacán. 